\title{
Diagnostic tools in childhood malaria
}

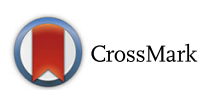

\author{
Amirah Amir, Fei-Wen Cheong, Jeremy R. De Silva and Yee-Ling Lau*
}

\begin{abstract}
Every year, millions of people are burdened with malaria. An estimated 429,000 casualties were reported in 2015, with the majority made up of children under five years old. Early and accurate diagnosis of malaria is of paramount importance to ensure appropriate administration of treatment. This minimizes the risk of parasite resistance development, reduces drug wastage and unnecessary adverse reaction to antimalarial drugs. Malaria diagnostic tools have expanded beyond the conventional microscopic examination of Giemsa-stained blood films. Contemporary and innovative techniques have emerged, mainly the rapid diagnostic tests (RDT) and other molecular diagnostic methods such as PCR, qPCR and loop-mediated isothermal amplification (LAMP). Even microscopic diagnosis has gone through a paradigm shift with the development of new techniques such as the quantitative buffy coat (QBC) method and the Partec rapid malaria test. This review explores the different diagnostic tools available for childhood malaria, each with their characteristic strengths and limitations. These tools play an important role in making an accurate malaria diagnosis to ensure that the use of anti-malaria are rationalized and that presumptive diagnosis would only be a thing of the past.
\end{abstract}

Keywords: Childhood, Malaria, Diagnosis, Microscopy, PCR, RDT

\section{Background}

First described in $2700 \mathrm{BC}$ and recognized as one of the oldest known diseases on our planet, malaria is still a cause of devastation in many parts of the world [1]. Malaria is caused by a protozoan parasite of the genus Plasmodium [2]. The five Plasmodium species which cause malaria in humans are $P$. falciparum, $P$. vivax, $P$. malariae, P. ovale and P. knowlesi [3]. The former three species are distributed across Africa, Asia and South and Central America, whereas P. ovale is found in Africa and $P$. knowlesi in Asia [4]. Despite sharing the same geographical distribution, $P$. vivax infection is less frequently found in Africa compared to P. falciparum, but is the dominant species causing malaria in many regions outside Africa [4]. All five species are known to infect children [3, 5-7], with falciparum malaria being responsible for the majority of malaria-related deaths. Although the World Health Organization (WHO) has reported a fall in incidence and malaria deaths among populations at risk between the years 2010 and 2015, the estimated number of malaria deaths in 2015 remained high with a number close to 429,000 , of which more than two thirds were in children under the age of five years old $[8,9]$.

\footnotetext{
* Correspondence: lauyeeling@um.edu.my

Department of Parasitology, Faculty of Medicine, University Malaya, 50603 Kuala Lumpur, Malaysia
}

Generally, children with malaria often present with fever, chills, headache, myalgia, vomiting and anorexia $[3,10]$. Although severe malaria is often associated with $P$. falciparum, $P$. vivax monoinfection and mixed $(P$. falciparum and $P$. vivax) infection can also develop into severe malaria in children, as they too demonstrate respiratory distress, anemia and neurological manifestation [11]. While severe malaria has been reported in adults infected with $P$. knowlesi [12], little is known in children. Existing data showed that most children present with thrombocytopenia and anemia but did not show any progression into severe malaria $[5,13]$. On the other hand, the least common $P$. malariae and $P$. ovale generally cause fever but the child does not appear ill [14].

Due to the non-specific manifestation of malaria infection, it is sometimes mistaken for gastroenteritis, pneumonia or sepsis [3, 15-17]. In contrast, since the symptoms of malaria are also exhibited by other microbial infection presenting with acute febrile illness, this may result in overestimation of malaria burden [18]. Diagnosis made based on clinical findings alone (presumptive diagnosis) may be unreliable and confirmatory laboratory diagnosis using diagnostic tools is crucial to ensure the accuracy of malaria diagnosis, thus, allowing administration of appropriate treatment [19]. Presumptive diagnosis has been shown to lead to over diagnosis 
and over treatment of malaria in children aged $1-5$ years $[20,21]$. Inappropriate use of antimalarial drugs in the past has led to the emergence of resistant malaria parasites [22, 23]. The newer 'magic bullet', artemisinin is not spared as $P$. falciparum in Myanmar, Cambodia, Thailand, Vietnam, Lao People's Democratic Republic are seen to develop resistance [22, 24]. Furthermore, the latest WHO guidelines for the treatment of malaria has recommended artemisinin-based combination therapy (ACT) for adults and children [25]. Therefore, the WHO has come up with several recommendation under the Global Plan for Artemisinin Resistance Containment (GPARC) which include improving access to affordable and quality-assured malaria diagnostic tools to ensure that only confirmed cases receive treatment [26]. Suggestions have been made to change the policy from presumptive malaria treatment to laboratory-confirmed diagnosis and treatment [27-30]. In addition to being able to avoid unnecessary adverse reaction to antimalarial drugs, a laboratory-confirmed diagnosis and treatment also reduces drug wastage and minimizes the risk of parasite resistance development [31]. Over the years, malaria diagnostic tools have expanded, from the conventional microscopic examination of Giemsa-stained blood films to a myriad of serological and molecular methods which include the more commonly used rapid diagnostic tests (RDTs) and polymerase chain reaction (PCR) [19]. This review explores the different diagnostic tools currently available for childhood malaria with the aim of updating clinicians and researchers alike. With the array of diagnostic tools available, it is important that we work towards reducing presumptive diagnosis.

\section{Microscopic diagnosis}

Accurate diagnosis with rapid and effective treatment is particularly important in children with malaria as most deaths occur within the first $24 \mathrm{~h}$ after admission to the hospital [32]. Direct microscopic observation of patients' blood to detect malaria parasite remains the gold standard for malaria diagnosis [33, 34]. Microscopic examination of a stained thick blood film is done to determine the presence or absence of malaria parasite, whereas microscopic examination of a stained thin blood film allows Plasmodium species identification and parasitaemia quantification. Microscopic examination could also provide pathophysiological and prognostic information that can serve as indicators for the severity of disease, such as the morphological characteristics of the parasites, the maturity of asexual stages of the parasite and circulating pigment-containing phagocytes $[35,36]$. The microscopic technique is widely used as it requires only a small volume of blood and it is cost effective compared to molecular techniques. Ngasala et al. [37] showed that microscopic diagnosis is useful in primary healthcare facilities as it helped to improve the appropriate management of non-malarial fevers and reduced the prescription of antimalarial drugs to children in Tanzania.

In ideal conditions, at least three negative serial blood smears (repeated every $12 \mathrm{~h}$ for $48 \mathrm{~h}$ ) are needed before malaria diagnosis can be excluded [38, 39]. The detection limit of a well-trained microscopist can be as low as 5 parasites/ $\mu$ l blood, while average laboratory personnel may only report a positive blood smear at 50-100 parasites/ $\mu$ l of blood $[14,40]$. The sensitivity and specificity of microscopic diagnosis varies greatly and are dependent on many factors. Ngasala et al. [37] showed that when 934 slides were examined by different microscopists, the overall sensitivity and specificity for detection of childhood malaria is $74.5 \%$ (95\% CI: $69.8-78.7 \%$ ) and $59.0 \%$ (95\% CI: 54.9-62.9\%), respectively, with a positive predictive value of $53.4 \%$ (95\% CI: 49.0-58.0\%) and a negative predictive value of $78.6 \%$ (95\% CI: $74.0-$ $82.0 \%)$. A study performed in Tanzanian children demonstrated that by comparing microscopy with RDTs and PCR, the sensitivity of conventional microscopy to detect pediatric malaria ranged from 26.3 to $100 \%$, with the specificity ranged from 91.7 to $100 \%$ [41]. Discrepancy has also been found when microscopy and RDT yielded a positive result of 17 and 30\%, respectively, in 515 Kenyan primary school children [42], whereas microscopy detected a $30 \%$ malaria prevalence in $230 \mathrm{Ni}$ gerian children compared to $24.3 \%$ using RDT [43]. Besides, the lack of malaria microscopist experts is another crucial factor in contributing to false reporting and errors in species identification. Plasmodium knowlesi, the fifth human Plasmodium could easily be misdiagnosed as $P$. malariae or $P$. falciparum under microscopy due to their morphological similarities [44]. Some children who were initially diagnosed with $P$. malariae infection via microscopy were confirmed to have $P$. knowlesi infection instead after PCR [5, 13]. These misdiagnoses could result in treatment delay and even fatal complications, as $P$. knowlesi can cause hyperparasitaemia within a short period of time and it causes a more severe disease compared to $P$. malariae. Sitali et al. [45] demonstrated that children under five years old have a higher frequency of acquiring mixed infection (infection with more than one Plasmodium species). However, mixed infections are often unrecognized or under-estimated by microscopists due to the tendency of one species dominating the other. This could lead to inadequate antimalarial drug treatment, particularly hypnozoites of $P$. vivax and $P$. ovale, the dormant form of parasites that can remain in the liver for many years, which can cause relapse. Difficulties in detecting parasites in low parasite density samples, overloaded laboratory personnel, ineffective quality control and assurance, poor condition of microscopes, and improper slide preparation can also lead to unreliable microscopy results [34, 46-48]. 
Besides the conventional bright field microscopic examination, additional techniques have been designed to improve malaria diagnosis via microscopy. The quantitative buffy coat (QBC) method is used to identify malaria parasites in peripheral blood by staining the DNA of parasites with acridine orange. QBC was found to be able to detect malaria in samples with low parasite numbers, as low as 5 parasites/ $\mu$ l blood [49]. Several studies proposed that $\mathrm{QBC}$ has a higher sensitivity compared to conventional microscopic examination in detecting malaria infection. Bosch et al. [50] demonstrated that QBC has a $100 \%$ sensitivity compared to microscopy examination in 37 indigenous children in Venezuela. Another study evaluated QBC on 720 schoolchildren and revealed a $99.6 \%$ sensitivity and $81.7 \%$ specificity on this technique, with $5.5 \%$ more sensitive than thick-film microscopic examination [51]. Similar results were obtained by Oloo et al. [52] where the overall sensitivity and specificity for QBC was 98 and 84\% respectively, in a malaria survey performed on 360 Western Kenyan schoolchildren, with an accuracy of $92 \%$ and negative predictive value of $98 \%$. Possible drawbacks of QBC are the difficulties in parasite species differentiation and subjective parasite quantification [53, 54]. Nonetheless, with its relatively reliable high sensitivity and specificity, QBC could still be useful as a supportive malaria diagnostic tool together with blood film microscopic screening in endemic field, as the processing of QBC is easier, faster, and requires less-trained personnel as compared to conventional microscopic examination [55-57]. For example in large-scale malaria screening, QBC could be performed prior to conventional bright-field microscopic examination to detect the presence of malaria parasites. Once malaria diagnosis has been established by the QBC, thin blood smears can then be used for accurate species identification and quantification of parasitaemia.

Another microscope-related technique, the Partec Rapid Malaria Test (PT) utilizes the Partec CyScope (Partec GmbH, Münster, Germany), a microscope that has an extra incident UV light for detection of fluorescence light. The test slides used is readily labelled with an unspecific DNA binding fluorescent dye, 4'-6-diamidino-2- phenylindole (DAPI), that binds to intraerythrocytic Plasmodium DNA resulting in fluorescence. This method is easy and rapid, less labour intensive and requires less training time for laboratory personnel. Besides, the Partec CyScope ${ }^{\odot}$ operates with integrated rechargeable batteries, which is convenient to be used in fields without electricity supply. Furthermore, it only requires few microliters of blood sample, which is ideal in paediatric patients. By using real-time PCR as gold standard, comparison study performed by Nkrumah et al. [58] in 489 children in Ghana reported the sensitivities of PT and microscopy examination were $62.2 \%$
(95\% CI: 56.3-67.8\%) and 61.8\% (95\% CI: 55.9-67.4\%), respectively, for detection of malarial infections, with their specificities of $96.0 \%$ (95\% CI: 92.3-98.3\%) and 98.0\% (95\% CI: 95.0-99.5\%), respectively. In a study of 541 Cameroonian schoolchildren using light microscopy as reference, PT was found to be $91.3 \%$ sensitive and $86.7 \%$ specific for detection of malaria [59]. Another study with 107 Plasmodium sp.-positive samples by microscopy demonstrated that both the sensitivity and specificity of PT for detection of childhood malaria [100\% (95\% CI: 96.6-100\%) and 97.4\% (95\% CI: 93.6-99.3\%), respectively] are higher than the sensitivity and specificity of RDT Binax Now ${ }^{\circledast}$ [97.2\% (95\% CI: 92.0-99.4\%) and $93.6 \%$ (95\% CI: 88.5-96.9\%), respectively] [60]. Comparable sensitivity and specificity of PT to microscopic examination and RDT thus led to the proposal of using PT as an alternative malaria diagnostic tool in endemic areas. However, species differentiation could not be done using this test. Besides, the presence of nonspecific artefacts, nuclei-containing cells such as reticulocytes, leukocytes and bacterial cells are very likely to lead to false positive results.

Conventional microscopy examination encounters many challenges, particularly the lack of trained malaria microscopists which could then lead to false diagnosis. To overcome this deficit, large efforts have been made in invention of computer-vision-based techniques and systems. These systems could function as "automated microscopists" and could greatly improve the speed, consistency and accuracy in malaria diagnosis. For instance, digital imaging scanning can be performed by SightDx first generation P1 and second generation P2 systems in which blood samples on test slides would be scanned automatically by the device with pre-set algorithms to detect the malaria parasites. These systems were able to scan the entire slide within few minutes, determine the parasitemia level and identify the Plasmodium species, with the performance result on par with human microscopist experts and many commercial RDTs [61, 62]. Recently, the latest commercial device Parasight platform was evaluated and demonstrates improved accuracy over the previous prototype P1 and P2 devices [63]. Despite above mentioned advantages, these computerized malaria diagnostic systems have yet to be evaluated on large scale.

\section{Rapid diagnostic tests}

The RDT is an effective and important tool in malaria diagnosis and is increasingly seen as a complement to traditional diagnosis by microscopy. It forms the mainstay of diagnosis in resource-poor areas which do not have access to a laboratory or electricity and in these settings may supersede microscopy for diagnosis of malaria. According to the WHO, there are more than 200 
malaria RDT products in the market [64] many of which have been assessed by independent studies according to WHO guidelines. According to the World Malaria Report 2015 [65], there were a total of 314 million RDT sales in 2014 and numbers are expected to increase over the years as the efficiency of these marketed RDTs increase.

Most RDTs work on the principle of capillary action. A capture and a separate detection antibody are used to provide a visual result where the capture antibodies are laid as a stripe on the membrane and the detection antibody is conjugated to an indicator, typically gold particles, that bind to the parasite antigen. This antigendetection antibody complex binds to the capture antibody producing a visible line if the targeted antigen is present in the clinical sample [66]. Most RDTs are able to detect malaria antigens in 5-15 $\mu \mathrm{l}$ of blood and results can be obtained in 5-20 min depending on the manufacturer's instructions. The detection limits for RDTs vary depending on individual manufacturers and the quality and the sensitivity of the RDTs depend on such factors as storage conditions, temperature and time of the assay [67].

There are currently three established antigens used for detection of Plasmodium in RDTs: P. falciparum histidine rich protein II (HRP-2), Plasmodium lactate dehydrogenase (pLDH) and aldolase. The HRP-2 protein is specific for P. falciparum detection while the pLDH and aldolase antigens are pan-malarial. Thus, most RDTs incorporate two of the three antigens to allow users to distinguish falciparum from non-falciparum infections. HRP-2 is a water soluble protein produced by asexual stages and young gametocytes of $P$. falciparum [68]. The pLDH enzyme on the other hand is produced by the sexual and asexual stages of Plasmodium and different isomers for this protein have been detected in various Plasmodium species [69]. Aldolase is an antigen utilized in the parasite glycolytic pathway and like pLDH is panmalarial as well [70].

The HRP-2 antigen has been shown to have better sensitivity compared to pLDH although specificity was found to be better with pLDH [71]. Furthermore, HRP-2 is less expensive, has a lower detection threshold and is stable at a wider range of temperatures thus making it the more widely used antigen [72]. The drawbacks of this antigen however, are that it only is able to detect $P$. falciparum infection and any antigenic variation may give a false-negative result [73]. Furthermore, HRP-2 antigens are known to still be in the circulation of the patient weeks after clearance of the parasite [74] thus making it unsuitable to be used in assays for monitoring response to drug treatment.

More recently, there have been reports of deletions of the HRP-2 in several areas endemic for P. falciparum infection. The prevalence of parasites with the HRP-2 gene deletions may, however, vary in differing localities. HRP-2 deletions leading to false negative reports have been published in Mali [75], Rwanda [76], Colombia [77], Ghana [78], Kenya [79], the Democratic Republic of Congo [80] and India [81]. Guidelines issued by the WHO, however, indicate that deletion of the HRP-2 gene is not likely to be the main cause of false-negative results in RDTs and point towards other more probable causes including poor transport and storage conditions, operator errors, or the use of poor quality RDTs or the use of a wrong comparator such as poor-quality microscopy for cross-referencing of negative diagnostic results [82]. The guidelines do state that HRP-2 deletion should be suspected in a specific number of instances and PCR may be used to confirm the diagnosis and the deletion of the HRP-2 gene.

The use of RDTs for malaria diagnosis in children suffer the same limitations that affect the use of the diagnostic method in adults. The primary limitations of this test include reduced sensitivity for non-falciparum malaria, and a lack of accuracy in extreme environmental conditions such as those found in field situations where it ironically is used the most [83, 84]. However, the RDT's ease of use and interpretation and its ability to be deployed in the field makes it an invaluable tool for diagnosis of malaria in children in rural areas. A study by Smart et al. [85] on pediatric inpatients in a two Tanzanian referral hospitals found moderate agreement between the use of microscopy and RDT for diagnosis of patients but suggested that RDT are a better initial test in diagnosing malaria among pediatric patients. The author also argues that the use of RDT would reduce the rate of overtreatment in hospitals in Tanzania which indirectly would provide a significant cost saving. Furthermore, withholding antimalarial drugs from children who test negative in an RDT test is a safe practice in an outpatient setting [86]. The use of RDT in hospitals would also decrease turn-around time providing physicians with feedback and results in a timely manner. Overtreatment of children was also reported in Samara hospital, Nigeria where $57 \%$ of febrile children admitted to the hospital received antimalarial medication for treatment of presumed malaria before the presentation [87]. When evaluating the sensitivity and specificity of RDT for diagnosis of pediatric malaria, the authors found that RDT had a sensitivity of $40.3 \%$ and a specificity of $89.6 \%$. However, it was of note that the sensitivity of the test dropped drastically with lower parasite densities. These results were contradictory to a previous study on the effectiveness of RDT in febrile children in Sokoto, Nigeria, where sensitivity of RDT was found to be 93\% [88].

Recent advancements in RDTs for malaria diagnosis include the development of the ultra sensitive rapid 
diagnostic test (uRDT) which has higher sensitivity compared to the conventional RDTs. A recent study by Das et al. [89] on the Alere ${ }^{\mathrm{Tm}}$ Malaria Ag P.f uRDT showed a greater than 10-fold lower detection limit for the HRP-2 antigen compared to a conventional RDT in both a high and low transmission setting. The study also indicates high specificitiy for this uRDT relative to quantitative PCR (qPCR) and histidine-rich protein II (HRP2) enzyme linked immunosorbent assay (ELISA). Furthermore, the uRDT was able to detect new infections 1.5 days sooner indicating overall improved diagnostic performance characteristics when compared to conventional RDTs [89].

Overall, studies on the sensitivity and specificity of RDT in diagnosing malaria have been positive in both a laboratory and outpatient clinical setting [90-92] and thus should be considered a useful tool for pediatric malaria diagnosis.

\section{Molecular diagnostic methods}

Molecular techniques, such as PCR, have gained much attention and significance in malarial diagnosis, especially after the discovery of knowlesi malaria in humans $[93,94]$. This method enables the specific identification of malarial parasites up to the species level. Furthermore, it is highly sensitive when compared to microscopy. The theoretical detection limit of PCR can be as low as 0.02 parasites/ $\mu l[95,96]$ with nested PCR being the most sensitive nucleic acid amplification technology thus far [41, 97] versus an experienced microscopist, which is said to have a detection limit of approximately 5 parasites/ $\mu$ l [40]. With other diagnostic methods falling short in terms of practicality, cross-reactivity problems, or having incomplete coverage of all medically important Plasmodia [98, 99], PCR-based methods seem promising as the new gold standard in malarial diagnosis, especially in cases with low parasitemia or in the case of mixed species [100].

The molecular amplification of the small subunit, 18S, of ribosomal RNA (18SrRNA) was first carried out by Snounou et al. [101] using a nested PCR technique, the most widely-used PCR method in malarial diagnostic research. The sensitivity of this molecular method was found to be greater than RDTs and microscopy in a study conducted by Mens et al. [102]. In their work, 338 children with the clinical symptoms of Plasmodium infection in Tanzania and Kenya were analyzed with microscopy, RDT, or molecular method. Molecular testing found a substantially higher amount of positive samples compared with RDTs and microscopy, confirming the elevated sensitivity of PCR [103] which enabled the identification of more children with low parasitemia. Around $40-42 \%$ the samples collected in Kenya were found positive with molecular methods, with parasite counts ranging from 16 to
108 parasites/ml blood. Similarly in Tanzania, 13-14 samples were found positive with molecular methods with parasite counts ranging from 9 to 170,000 parasite $/ \mathrm{ml}$ blood. Additionally, molecular methods have the potential to detect malarial parasites in asymptomatic infections. These undetected sub-microscopic infections, though less common in children than in adults, may still be able to infect mosquito vectors and could reintroduce malaria into certain regions. Semi-nested PCR based on the $18 \mathrm{~S}$ small subunit ribosomal RNA (ssrRNA) gene permitted the identification of a high number of children $(80 \%)$ infected with $P$. falciparum. These children had all initially tested negative with the microscopy method [104]. Interestingly, others have found the high copy number of cytochrome $b$ PCR to be more sensitive than $18 S$ rDNA PCR [41, 105, 106]. Hsiang et al. [107] detected three times as many infections with cytochrome $b$ nested PCR than by microscopy (15/472 vs 4/472) among asymptomatic children with lowest detection limit of 10 parasites/ $\mu$ l. This technique also performed better than single-round PCR and real-time methods [107]. A more recent study by Mahende et al. [108] determined 21 malaria RDT-positive samples from Tanzanian children while microscopy was negative; six samples were detected positive by $18 S$ rDNA PCR [108]. Of note is that eight samples that were RDTnegative but microscopy-positive were confirmed to possess $P$. falciparum species through PCR. Threequarters of the 867 malaria patients from this study had low levels of parasitaemia. Therefore, PCR is a worthy alternative as the interpretation of the results either by agarose gel observation or $\mathrm{Ct}$ value does not require specialized skill and is not altered by the subjectivity of the observer [95]; this is the precise opposite to microscopy where specific training is required for species differentiation.

The specificity of PCR has also been demonstrated by Nsobya et al. [109]. Upon enrollment, 55 (17\%) of 316 asymptomatic children in Uganda were found to be infected with $P$. falciparum via microscopy (parasite densities was $16-71,840$ parasites $/ \mathrm{ml}$ ). By using species-specific nested PCR, the prevalence of malaria was observed to be 148 (47\%), of which $36 \%$ were P. falciparum, 18\% P. falciparum mixed infection, $10 \% P$. ovale, $7 \% P$. vivax, $4 \% P$. malariae, and $3 \%$ non-P. falciparum mixed infection. Two children were PCR negative but microscopy positive [109].

Real-time quantitative PCR (qPCR) and nucleic acid sequence-based amplification (QT-NASBA) assays can also be utilized to determine parasite density. The advantage of qPCR over other molecular techniques is the quantification of parasitic densities. By correlating quantification by two commercial qPCR (PrimerDesign Ltd., Alicante, Spain) kits, Santana-Morales et al. [109] confirmed that qPCR is an accurate means to quantify 
parasitic densities. One case of imported falciparum malaria was reported in France in a boy that visited his family in Africa during a summer break. qPCR quantified $P$. falciparum DNA levels in an effort to monitor the parasitemia under treatment and to determine chloroquine resistance. qPCR was able to detect and quantify infections that have very low infection $(0.001 \%)$ [110]. qPCR assays targeting the high-copy telomere-associated repetitive element 2 (TARE-2) and the var. gene acidic terminal sequence (varATS) were also developed for ultra-sensitive detection of P. falciparum. Compared to TARE-2 or varATS qPCR, $18 S$ rRNA gene qPCR was unable to identify 48 infections in 498 samples from a malaria survey undertaken in Tanzania [111].

In a recent report, a reverse transcription-polymerase chain reaction (qRT-PCR) was developed for the asexual $18 S$ rRNAs of $P$. falciparum and $P$. vivax. qRT-PCR demonstrated high sensitivity as compared to qPCR by detecting 34/52 symptomatic patients and 13/36 asymptomatic patients [112]. Other molecular techniques developed for malaria diagnosis include loop-mediated isothermal amplification (LAMP), flow cytometry, and microarray [113-115]. However, the efficiency of these methods has not been established for childhood malaria.

A lack of clear consensus on standardized methods for PCR makes it difficult to interpret and compare results. There is a need to develop guidance on indications for use, assay selection, and quality assurance/control for PCR and other molecular diagnostic techniques for the specific conditions in which employing malaria diagnostic tools may be appropriate. To ensure the data obtained from PCR-based method are reliable, users are strongly encouraged to follow the WHO external quality assurance scheme for malaria nucleic acid amplification testing [116]. Another drawback is that PCR is cumbersome, expensive, and requires well-trained staff with stringent laboratory cleanliness. Such criteria may not be fulfilled in certain laboratory settings, especially those in remote areas in developing countries [117].

\section{Non-invasive tests}

The future of malaria diagnostic tools is exciting as we start to see the development of new non-invasive methods. One such method is by detecting specific thioeter levels in human breath which acts as biomarkers. Exhaled breath is analyzed using gas chromatographymass spectrometry. An early clinical trial of this method on adult volunteers infected with P. falciparum showed promising results with thioether levels appearing to have the same periodicity as the parasite's $48 \mathrm{~h}$ erythrocytic life-cycle [118].

The urine malaria test (UMT) kit, a recombinant monoclonal antibody based test was also recently developed to detect $P$. falciparum specific HRP-2, a poly- histidine protein or fragments present in the urine of febrile patients. Similar to most RDTs, UMT works on the principle of capillary action. This method involves dipping the UMT strip into $200 \mu \mathrm{l}$ urine for $2 \mathrm{~min}$ and results read after 20 min based on the lines appearing on the strip. Initial assessment on patients in South-East Nigeria showed that it was comparable with the microscopy technique [119]. Another multicenter UMT trial in Lagos state, Nigeria, managed to include patients infected with $P$. falciparum, $P$. vivax, $P$. malaria and $P$. ovale [120]. Here, they found that UMT sensitivity and specificity was 93 and $83 \%$, respectively, when used among febrile children under the age of five. The performance of the UMT in this study was found to be comparable with that of BinaxNow, a blood-based malaria RDT.

Several studies involving a mixed population consisting of adults and children have tried using urine and saliva as alternative DNA sources for malaria diagnosis by PCR with promising results $[121,122]$. Furthermore, saliva has also been used for the quantitative detection of $P$. falciparum HRP-2 antigen using ELISA with encouraging outcome [123, 124].

Another fascinating method recently developed was the transdermal detection of vapor nanobubbles around intraparasite hemozoin using a prototype device [125]. This method involves delivering laser pulses to blood through the skin using a probe after which, the responding acoustic traces are collected simultaneously with laser irradiation and analyzed.

These non-invasive methods serve as a potential alternative tool in malaria diagnosis especially where there are difficulties in obtaining blood samples (particularly in children), problems with carrying out conventional diagnostic method or when safety concerns are expressed. However, most of these non-invasive tests are still at their infancy and there is a need for optimization of the technology and further testing to also include field-acquired infection and paediatric populations.

\section{Conclusions}

The characteristic features of microscopic diagnosis, rapid diagnostic test and molecular diagnostic methods are summarized in Table 1. Despite the progress and advancement of various malaria diagnostic tools, the microscopy technique remains the gold standard for malaria diagnosis. RDTs prove to be valuable as it can be undertaken without any basic laboratory infrastructure or trained personnel. The ability of RDTs to produce results within a few minutes help reduce over-treatment or misdiagnosis from presumptive diagnosis. Nevertheless, because of the variable sensitivity and specificity of different RDTs, WHO procurement guidelines should be followed when procuring malaria RDTs and a good 


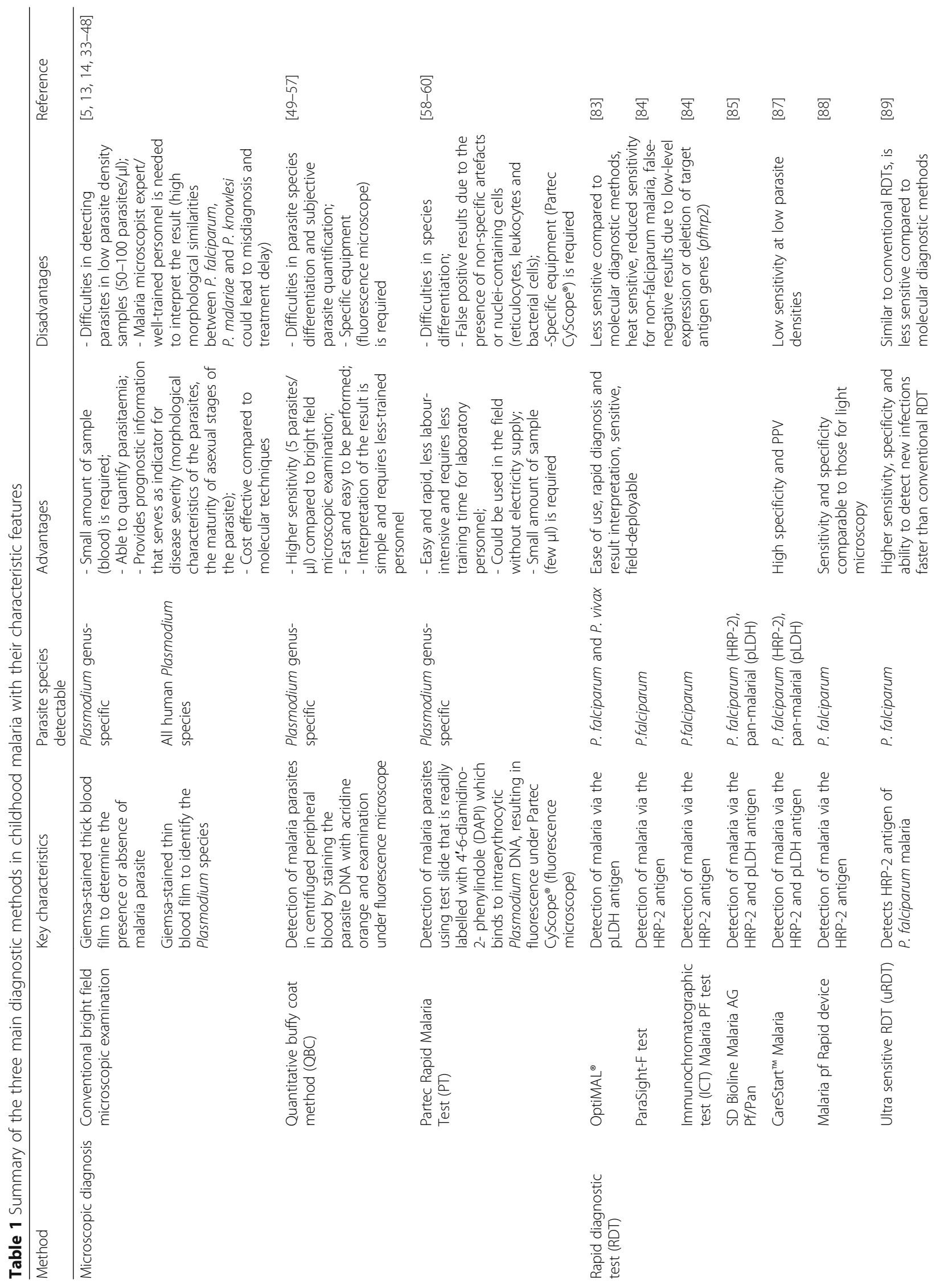




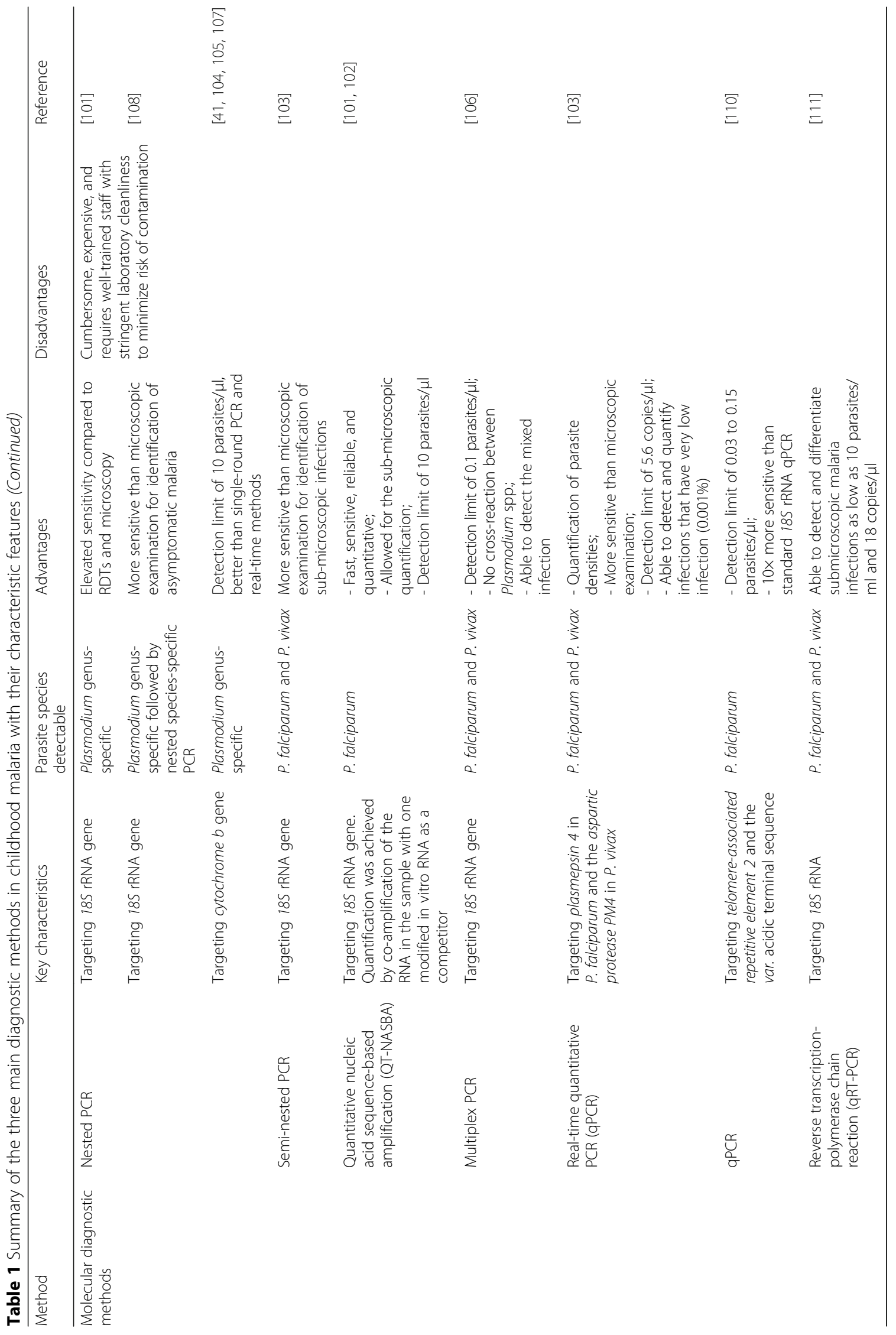


quality control/assurance programme should be implemented. The highly sensitive and specific results obtained from PCR makes it a good candidate as the next gold standard for malaria diagnosis. However, due to it being costly, requiring trained personnel and a proper laboratory setting, this method is not practical especially in rural or out-patient settings. Light microscopy and RDTs are still the mainstay of malaria diagnosis in basic healthcare systems, whereas molecular methods may be utilized in advanced healthcare systems as part of malaria diagnostic protocol. In elimination settings, molecular methods are required to complement field diagnostics (microscopy and RDTs) in order to identify asymptomatic carriers which is critical to the success of elimination programmes [126].

\section{Abbreviations}

LAMP: Loop-mediated isothermal amplification; PCR: Polymerase chain reaction; QBC: Quantitative buffy coat; GPCR: Real-time quantitative polymerase chain reaction; RDT: Rapid diagnostic tests

\section{Acknowledgements}

Not applicable.

\section{Funding}

AA was supported by BKP grant, University of Malaya (BK013-2016). FWC was supported by BKP grant, University of Malaya (BK005-2017). JRDS was supported by the Fogarty International Center and the Office of AIDS Research at the National Institutes of Health under the Global Health Equity Scholars Consortium at Yale University (D43TW010540).

\section{Availability of data and materials}

Not applicable.

\section{Authors' contributions}

AA, FWC, JRDS and YLL wrote and revised the manuscript. All authors read and approved the final manuscript.

\section{Ethics approval and consent to participate}

Not applicable.

\section{Consent for publication}

Not applicable.

\section{Competing interests}

The authors declare that they have no competing interests.

\section{Publisher's Note}

Springer Nature remains neutral with regard to jurisdictional claims in published maps and institutional affiliations.

Received: 18 September 2017 Accepted: 2 January 2018

Published online: 23 January 2018

\section{References}

1. Centers for Disease Control and Prevention CDC. The history of malaria, an ancient disease March 11, 2016. 2016. https://www.cdc.gov/malaria/about/ history/. Accessed 10 June 2017.

2. Neva FA, Brown HW. Basic clinical parasitology. Appleton \& Lange: Norwalk, Connecticut; 1994

3. Crawley J, Chu C, Mtove G, Nosten F. Malaria in children. Lancet. 2010;375: 1468-81.

4. IARC Working Group on the Evaluation of Carcinogenic Risks to Humans. Malaria and some polyomaviruses (SV40, BK, JC, and Merkel cell viruses). IARC Monogr Eval Carcinog Risks Hum. 2014;104:41-53.
5. Barber BE, William T, Jikal M, Jilip J, Dhararaj P, Menon J, et al. Plasmodium knowlesi malaria in children. Emerg Infect Dis. 2011;17(5):814.

6. Mahgoub H, Gasim GI, Musa IR, Adam I. Severe Plasmodium vivax malaria among Sudanese children at new Halfa hospital, eastern Sudan. Parasit Vectors. 2012;5:154.

7. Doctor SM, Liu Y, Anderson OG, Whitesell AN, Mwandagalirwa MK, Muwonga J, et al. Low prevalence of Plasmodium malariae and Plasmodium ovale mono-infections among children in the Democratic Republic of the Congo: a population-based, cross-sectional study. Malar J. 2016;15(1):350.

8. World Health Organization. Malaria in children under five 6 April 2016. 2016. http://www.who.int/malaria/areas/high_risk_groups/children/en/. Accessed 10 June 2017.

9. World Health Organization. Malaria Fact Sheet April 2016. 2016. http://www. who.int/malaria/media/world-malaria-report-2016/en/. Accessed 10 June 2017.

10. Rodríguez-Morales AJ, Sánchez E, Vargas M, Piccolo C, Colina R, Arria M. Anemia and thrombocytopenia in children with Plasmodium vivax malaria. J Trop Pediatr. 2006;52(1):49-51.

11. Genton B, D'Acremont V, Rare L, Baea K, Reeder JC, Alpers MP, et al. Plasmodium vivax and mixed infections are associated with severe malaria in children: a prospective cohort study from Papua New Guinea. PLoS Med. 2008;5(6):e127.

12. William T, Menon J, Rajahram G, Chan L, Ma G, Donaldson S, et al. Severe Plasmodium knowlesi malaria in a tertiary care hospital, Sabah, Malaysia. Emerg Infect Dis. 2011;17(7):1248-55.

13. Van den Eede P, Van HN, Van Overmeir C, Vythilingam I, Duc TN, Hung LX, et al. Human Plasmodium knowlesi infections in young children in central Vietnam. Malar J. 2009;8(1):249.

14. Stauffer W, Fischer PR. Diagnosis and treatment of malaria in children. Clin Infect Dis. 2003;37(10):1340-8.

15. Källander K, Nsungwa-Sabiiti J, Peterson S. Symptom overlap for malaria and pneumonia - policy implications for home management strategies. Acta Trop. 2004;90:211-4.

16. Marsh K, Forster D, Waruiru C, Mwangi I, Winstanley M, Marsh V, et al. Indicators of life-threatening malaria in African children. N Engl J Med. 1995; 332(21):1399-404.

17. Hotchkiss RS, Karl IE. The pathophysiology and treatment of sepsis. N Engl J Med. 2003;348:138-50.

18. Ari MD, Guracha A, Fadeel MA, Njuguna C, Njenga MK, Kalani R, et al. Challenges of establishing the correct diagnosis of outbreaks of acute febrile illnesses in Africa: the case of a likely Brucella outbreak among nomadic pastoralists, northeast Kenya, march-July 2005. Am J Trop Med Hyg. 2011;85(5):909-12.

19. Onile-ere O, Openibo J, Olasehinde Gl, Malaria diagnosis: current approaches and future prospects. In: 3 rd International Conference On African Development Issues (CU-ICADI), May 9-May 11. Covenant University. Nigeria: Ota; 2016.

20. Oladosu OO, Oyibo WA. Overdiagnosis and overtreatment of malaria in children that presented with fever in Lagos, Nigeria. ISRN Infect Dis. 2012; 2013

21. Mwangi TW, Mohammed M, Dayo H, Snow RW, Marsh K. Clinical algorithms for malaria diagnosis lack utility among people of different age groups. Tropical Med Int Health. 2005;10:530-6.

22. Maude RJ, Woodrow CJ, White LJ. Artemisinin antimalarials: preserving the "magic bullet". Drug Dev Res. 2010;71:12-9.

23. Cui L, Mharakurwa S, Ndiaye D, Rathod PK, Rosenthal PJ. Antimalarial drug resistance: literature review and activities and findings of the ICEMR network. Am J Trop Med Hyg. 2015;93:57-68.

24. Ashley EA, Dhorda M, Fairhurst RM, Amaratunga C, Lim P, Suon S, et al. Spread of artemisinin resistance in Plasmodium falciparum malaria. N Engl J Med. 2014;371(5):411-23.

25. World Health Organization Guidelines for the treatment of malaria. 3rd edition. Geneva: world health Organization; 2015.

26. World Health Organization Global plan for artemisinin resistance containment (GPARC). Geneva: world health Organization; 2011.

27. D'Acremont V, Lengeler C, Mshinda H, Mtasiwa D, Tanner M, Genton B. Time to move from presumptive malaria treatment to laboratory-confirmed diagnosis and treatment in African children with fever. PLoS Med. 2009;6:e252.

28. English M, Reyburn H, Goodman C, Snow RW. Abandoning presumptive antimalarial treatment for febrile children aged less than five years - a case of running before we can walk? PLoS Med. 2009;6:e1000015.

29. Choge JK, Ng'Wena GM, Akhwale W, Koech J, Ngeiywa MM, Oyoo-Okoth E, et al. Symptomatic malaria diagnosis overestimate malaria prevalence, but 
underestimate anaemia burdens in children: results of a follow up study in Kenya. BMC Public Health. 2014;14(1):332.

30. Okoro C, Chukwuocha U, Nwakwuo G, Ukaga C. Presumptive diagnosis and treatment of malaria in febrile children in parts of south eastern Nigeria. J Infect Dis Ther. 2015;3:5.

31. Chukwuocha UM. Malaria treatment in children based on presumptive diagnosis: a make or mar?. J Pediatric Infect Dis. 2016;1:6.

32. Planche T, Krishna S, Kombila M, Engel K, Faucher JF, Ngou-Milama E, et al. Comparison of methods for the rapid laboratory assessment of children with malaria. Am J Trop Med Hyg. 2001;65(5):599-602.

33. Jonkman A, Chibwe RA, Khoromana CO, Liabunya UL, Chaponda ME, Kandiero GE, et al. Cost-saving through microscopy-based versus presumptive diagnosis of malaria in adult outpatients in Malawi. Bull World Health Organ. 1995;73(2):223-7.

34. Mbakilwa H, Manga C, Kibona S, Mtei F, Meta J, Shoo A, et al. Quality of malaria microscopy in 12 district hospital laboratories in Tanzania. Pathog Glob Health. 2012;106:330-4.

35. Silamut K, White NJ. Relation of the stage of parasite development in the peripheral blood to prognosis in severe falciparum malaria. Trans $\mathrm{R}$ Soc Trop Med Hyg. 1993;87:436-43.

36. Nguyen PH, Day N, Pram TD, Ferguson DJ, White NJ. Intraleucocytic malaria pigment and prognosis in severe malaria. Trans R Soc Trop Med Hyg. 1995; 89:200-4.

37. Ngasala B, Mubi M, Warsame M, Petzold MG, Massele AY, Gustafsson LL, et al. Impact of training in clinical and microscopy diagnosis of childhood malaria on antimalarial drug prescription and health outcome at primary health care level in Tanzania: a randomized controlled trial. Malar J. 2008;7:199.

38. Pasricha JM, Juneja S, Manitta J, Whitehead S, Maxwell E, Goh WK, et al. Is serial testing required to diagnose imported malaria in the era of rapid diagnostic tests? Am J Trop Med Hyg. 2013;88(1):20-3.

39. White NJ. The treatment of malaria. N Engl J Med. 1996;335(11):800-6.

40. Tangpukdee N, Duangdee C, Wilairatana P, Krudsood S. Malaria diagnosis: a brief review. Korean J Parasitol. 2009:47:93-102.

41. Strom GE, Haanshuus CG, Fataki M, Langeland N, Blomberg B. Challenges in diagnosing paediatric malaria in Dar es Salaam, Tanzania. Malar J. 2013;12:228.

42. Neumann CG, Bwibo NO, Siekmann JH, McLean ED, Browdy B, Drorbaugh $\mathrm{N}$. Comparison of blood smear microscopy to a rapid diagnostic test for invitro testing for $P$. falciparum malaria in Kenyan school children. East Afr Med J. 2008:85:544-9.

43. Audu HO, Abdulsalam MY. Detection of malaria parasites by microscopy and rapid diagnostic test kit (pLDH) in pregnant women and children, Lagos, Nigeria. Nig J Parasitol. 2015;36:137-40.

44. Lee KS, Cox-Singh J, Singh B. Morphological features and differential counts of Plasmodium knowlesi parasites in naturally acquired human infections. Malar J. 2009;8:73.

45. Sitali L, Chipeta J, Miller JM, Moonga HB, Kumar N, Moss WJ, et al. Patterns of mixed Plasmodium species infections among children six years and under in selected malaria hyper-endemic communities of Zambia: population-based survey observations. BMC Infect Dis. 2015;15:204.

46. Ohrt C, Purnomo Sutamihardja MA, Tang D, Kain KC. Impact of microscopy error on estimates of protective efficacy in malaria-prevention trials. J Infect Dis. 2002;186:540-6.

47. Wongsrichanalai C, Barcus MJ, Muth S, Sutamihardja A, Wernsdorfer WHA. Review of malaria diagnostic tools: microscopy and rapid diagnostic test (RDT). Am J Trop Med Hyg. 2007;77:119-27.

48. McKenzie FE, Sirichaisinthop J, Miller RS, Gasser RA Jr, Wongsrichanalai C. Dependence of malaria detection and species diagnosis by microscopy on parasite density. Am J Trop Med Hyg. 2003;69:372-6.

49. Pornsilapatip J, Namsiripongpun V, Wilde H, Hanvanich M, Chutivongse S. Detection of plasmodia in acridine orange stained capillary tubes (the QBC system). Southeast Asian J Trop Med Public Health. 1990;21:534-40.

50. Bosch I, Bracho C, Perez HA. Diagnosis of malaria by acridine orange fluorescent microscopy in an endemic area of Venezuela. Mem Inst Oswaldo Cruz. 1996;91:83-6.

51. Benito A, Roche J, Molina R, Amela C, Alvar J. Application and evaluation of QBC malaria diagnosis in a holoendemic area. Appl Parasitol. 1994;35: 266-72.

52. Oloo AJ, Ondijo SO, Genga IO, Boriga DA, Owaga ML, Ngare D, et al. Evaluation of the QBC method to detect malaria infections in field surveys. East Afr Med J. 1994;71:297-9.
53. Pinto MJ, Rodrigues SR, Desouza R, Verenkar MP. Usefulness of quantitative buffy coat blood parasite detection system in diagnosis of malaria. Indian J Med Microbiol. 2001;19:219-21.

54. Salmani MP, Preeti BM, Peerapur BV. Comparative study of peripheral blood smear and quantitative buffy coat in malaria diagnosis. J Commun Dis. 2011:43:57-9.

55. Chotivanich K, Silamut K, Day NPJ. Laboratory diagnosis of malaria infection - a short review of methods. N Z J. Med Lab Sci. 2007;61:4-7.

56. Prashanth GP. Quantitative buffy coat (QBC) test for rapid diagnosis of malaria. Eur J Pediatr. 2012;171:199-200.

57. Mirdha BR, Samantray JC, Burman D, Mishra B, Ghimire P. Quantitative buffy coat: a special adjunct for diagnosis of malaria. J Commun Dis. 1999;31:19-22.

58. Nkrumah B, Agyekum A, Acquah SE, May J, Tannich E, Brattig N, et al. Comparison of the novel Partec rapid malaria test to the conventional Giemsa stain and the gold standard real-time PCR. J Clin Microbiol. 2010;48: 2925-8.

59. Kimbi HK, Ajeagah HU, Keka FC, Lum E, Nyabeyeu HN, Tonga CF. Asymptomatic malaria in school children and evaluation of the performance characteristics of the Partec Cyscope ${ }^{\circledast}$ in the Mount Cameroon region. J Bacteriol Parasitol. 2012;3:153.

60. Nkrumah B, Acquah SE, Ibrahim L, May J, Brattig N, Tannich E, et al. Comparative evaluation of two rapid field tests for malaria diagnosis: Partec rapid malaria test ${ }^{\oplus}$ and Binax now ${ }^{\circledast}$ malaria rapid diagnostic test. BMC Infect Dis. 2011;11:143.

61. Srivastava B, Anvikar AR, Ghosh SK, Mishra N, Kumar N, Houri-Yafin A, et al. Computer-vision-based technology for fast, accurate and cost effective diagnosis of malaria. Malar J. 2015;14:526.

62. Houri-Yafin A, Eshel Y, Lezmy N, Larbi B, Wypkema E, Dayanand V, et al. An enhanced computer vision platform for clinical diagnosis of malaria. Malaria Contr Elimination. 2016:5:138.

63. Eshel Y, Houri-Yafin A, Benkuzari H, Lezmy N, Soni M, Charles M, et al. Evaluation of the Parasight platform for malaria diagnosis. J Clin Microbiol. 2017;55(3):768-75

64. World Health Organization. Rapid diagnostic tests. 14 July 2017. http://www.who. int/malaria/areas/diagnosis/rapid_diagnostic_tests/en/. Accessed 25 Sept 2017.

65. World Health Organization. World Malaria Report 2015. 2015. http://www. who.int/malaria/publications/world-malaria-report-2015/report/en/. Accessed 25 Sept 2016

66. Murray CK, Gasser RA Jr, Magill AJ, Miller RS. Update on rapid diagnostic testing for malaria. Clin Microbiol Rev. 2008;21(1):97-110.

67. World Health Organization. Malaria rapid diagnostic test performance: results of WHO product testing of malaria RDTs: round 6 (2014-2015). December 2015. http://www.who.int/malaria/publications/atoz/9789241510035/en/. Accessed 25 Sept 2016.

68. Rock EP, Marsh K, Saul AJ, Wellems TE, Taylor DW, Maloy WL, et al. Comparative analysis of the Plasmodium falciparum histidine-rich proteins HRP-I, HRP-II and HRP-III in malaria parasites of diverse origin Parasitology. 1987;95(2):209-27.

69. Makler MT, Piper RC, Milhous WK. Lactate dehydrogenase and the diagnosis of malaria. Parasitol Today. 1998;14(9):376-7.

70. Meier B, Dobeli H, Certa U. Stage-specific expression of aldolase isoenzymes in the rodent malaria parasite Plasmodium berghei. Mol Biochem Parasitol. 1992;52(1):15-27.

71. Abba K, Deeks JJ, Olliaro PL, Naing CM, Jackson SM, Takwoingi Y, et al. Rapid diagnostic tests for diagnosing uncomplicated $P$. falciparum malaria in endemic countries. Cochrane Database Syst Rev. 2011;6(7):CD008122.

72. Chiodini PL, Bowers K, Jorgensen P, Barnwell JW, Grady KK, Luchavez J, et al. The heat stability of plasmodium lactate dehydrogenase-based and histidine-rich protein 2-based malaria rapid diagnostic tests. Trans R Soc Trop Med Hyg. 2007;101(4):331-7.

73. Lee N, Baker J, Andrews KT, Gatton ML, Bell D, Cheng Q, et al. Effect of sequence variation in Plasmodium falciparum histidine-rich protein 2 on binding of specific monoclonal antibodies: implications for rapid diagnostic tests for malaria. J Clin Microbiol. 2006:44(8):2773-8.

74. Laferi $\mathrm{H}$, Kandel K, Pichler H. False positive dipstick test for malaria. N Engl J Med. 1997:337(22):1635-6.

75. Koita OA, Doumbo OK, Ouattara A, Tall LK, Konare A, Diakite M, et al. Falsenegative rapid diagnostic tests for malaria and deletion of the histidine-rich repeat region of the hrp2 gene. Am J Trop Med Hyg. 2012;86:194-8.

76. Kozycki CT, Umulisa N, Rulisa S, Mwikarago El, Musabyimana JP, Habimana JP, et al. False-negative malaria rapid diagnostic tests in Rwanda: impact of 
Plasmodium falciparum isolates lacking hrp2 and declining malaria transmission. Malar J. 2017:16:123.

77. Murillo Solano C, Akinyi Okoth S, Abdallah JF, Pava Z, Dorado E, Incardona $\mathrm{S}$, et al. Deletion of Plasmodium falciparum histidine-rich protein 2 (pfhrp2) and histidine-rich protein 3 (pfhrp3) genes in Colombian parasites. PLoS One. 2015;10:e0131576.

78. Amoah LE, Abankwa J, Oppong A. Plasmodium falciparum histidine rich protein-2 diversity and the implications for PfHRP 2: based malaria rapid diagnostic tests in Ghana. Malar J. 2016;15:101.

79. Beshir KB, Sepulveda N, Bharmal J, Robinson A, Mwanguzi J, Busula AO, et al. Plasmodium falciparum parasites with histidine-rich protein 2 (pfhrp2) and pfhrp3 gene deletions in two endemic regions of Kenya. Sci Rep. 2017; 7:14718.

80. Parr JB, Verity R, Doctor SM, Janko M, Carey-Ewend K, Turman BJ, et al. Pfhrp2-deleted Plasmodium falciparum parasites in the Democratic Republic of the Congo: a national cross-sectional survey. J Infect Dis. 2017;216:36-44.

81. Bharti PK, Chandel HS, Ahmad A, Krishna S, Udhayakumar V, Singh N. Prevalence of pfhrp2 and/or pfhrp3 gene deletion in Plasmodium falciparum population in eight highly endemic states in India. PLoS One. 2016;11(8):e0157949.

82. World Health Organization. False-negative RDT results and implications of new reports of $P$. falciparum histidine-rich protein 2/3 gene deletions. 2017. http://www.who.int/malaria/publications/atoz/information-note-hrp2-basedrdt/en/. Accessed 15 Nov 2017

83. Cooke AH, Chiodini PL, Doherty T, Moody AH, Ries J, Pinder M. Comparison of a parasite lactate dehydrogenase-based immunochromatographic antigen detection assay (OptiMAL) with microscopy for the detection of malaria parasites in human blood samples. Am J Trop Med Hyg. 1999;60(2): 173-6.

84. Murahwa FC, Mharakurwa S, Mutambu SL, Rangarira R, Musana BJ. Diagnostic performance of two antigen capture tests for the diagnosis of Plasmodium falciparum malaria in Zimbabwe. Cent Afr J Med. 1999. 45(4):97-100.

85. Smart LR, Orgenes $N$, Mazigo HD, Minde M, Hokororo A, Shakir M, et al. Malaria and HIV among pediatric inpatients in two Tanzanian referral hospitals: a prospective study. Acta Trop. 2016;159:36-43.

86. D'Acremont V, Kahama-Maro J, Swai N, Mtasiwa D, Genton B, Lengeler C. Reduction of anti-malarial consumption after rapid diagnostic tests implementation in Dar es Salaam: a before-after and cluster randomized controlled study. Malar J. 2011;10:107.

87. Abdulkadir I, Rufai HA, Ochapa SO, Malam MS, Garba BI, Oloko AG, et al. Malaria rapid diagnostic test in children: the Zamfara. Nigeria experience Niger Med J. 2015;56(4):278-82.

88. Sani UM, Jiya NM, Ahmed $\mathrm{H}$. Evaluation of a malaria rapid diagnostic test among febrile children in Sokoto, Nigeria. Int J Med Sci. 2013;3:433-40.

89. Das S, Jang IK, Barney B, Peck R, Rek JC, Arinaitwe E, et al. Performance of a high-sensitivity rapid diagnostic test for Plasmodium falciparum malaria in asymptomatic individuals from Uganda and Myanmar and naive human challenge infections. Am J Trop Med Hyg. 2017;97(5):1540-50.

90. Nwuba Rl, Anumudu Cl, Omosun YO, Sodeinde O, Nwagwu M. Evaluation of a rapid immunochromatographic card test for Plasmodium falciparum in Ibadan, Nigeria. Afr J Med Med Sci. 2001;30(1-2):123-4.

91. Beadle C, Long GW, McElroy PD, Hoffman SL, Weiss WR, Maret SM, et al. Diagnosis of malaria by detection of Plasmodium falciparum HRP-2 antigen with a rapid dipstick antigen-capture assay. Lancet. 1994;343(8897):564-8.

92. Huong NM, Davis TM, Hewitt S, Van Huong N, Uyen TT, Nhan DH, et al. Comparison of three antigen detection methods for diagnosis and therapeutic monitoring of malaria: a field study from southern Vietnam. Tropical Med Int Health. 2002;7(4):304-8.

93. Oddoux O, Debourgogne A, Kantele A, Kocken CH, Jokiranta TS, Vedy S, et al. Identification of the five human Plasmodium species including $P$. knowlesi by real-time polymerase chain reaction. J Clin Microbiol. Infect Dis. 2010;30:597-601

94. Ta TT, Salas A, Ali-Tammam M, del Carmen MM, Lanza M, Arroyo E, et al. First case of detection of Plasmodium knowlesi in Spain by real time PCR in a traveller from Southeast Asia. Malar J. 2010;9:219-24.

95. Rubio JM, Benito A, Berzosa PJ, Roche J, Puente S, Subirats M, et al. Usefulness of semi-nested multiplex PCR in surveillance of imported malaria in Spain. J Clin Microbiol. 1999;37:3260-4.

96. Schneider P, Wolters $L$, Schoone G, Schallig H, Sillekens $P$, Hermsen $R$, et al. Real-time nucleic acid sequence-based amplification is more convenient than real-time PCR for quantification of Plasmodium falciparum. J Clin Microbiol. 2005;43:402-5.

97. Mixson-Hayden T, Lucchi N, Udhayakumar V. Evaluation of three PCR-based diagnostic assays for detecting mixed Plasmodium infection. BMC Res Notes. 2010;3:88

98. Bell D, Wongsrichanalai C, Barnwell J. Ensuring quality and access for malaria diagnosis: how can it be achieved? Nat Rev Microbiol. 2006;4:S7-S20.

99. Abramo C, Fontes CJ, Krettli AU. Cross-reactivity between antibodies in the sera of individuals with leishmaniasis, toxoplasmosis and Chagas's disease and antigens of the blood-stage forms of Plasmodium falciparum determined by indirect immunofluorescence. Am J Trop Med Hyg. 1995;53:202-5.

100. Pilcher C, Eron J, Galvin S, Gay C, Cohen M, Acute HIV. Revisited: new opportunities for treatment and prevention. J Clin Invest. 2004;113:937-45.

101. Snounou G. Detection and identification of the four malaria parasite species infecting humans by PCR amplification. Methods Mol Biol. 1996;50:263-91.

102. Mens P, Spieker N, Omar S, Heijnen M, Schallig H, Kager P. Is Molecular biology the best alternative for diagnosis of malaria to microscopy? A comparison between microscopy, antigen detection and molecular tests in rural Kenya and urban Tanzania. Tropical Med Int Health. 2007;12:238-44.

103. Schoone GJ, Oskam L, Kroon NC, Schallig HD, Omar SA. Detection and quantification of Plasmodium falciparum in blood samples using quantitative nucleic acid sequence-based amplification. J Clin Microbiol. 2000;38(11):4072-5.

104. Santana-Morales MA, Afonso-Lehmann RN, Quispe MA, Reyes F, Berzosa P, Benito A, et al. Microscopy and molecular biology for the diagnosis and evaluation of malaria in a hospital in a rural area of Ethiopia. Malar J. 2012;11:199.

105. Hasan AU, Suguri S, Sattabongkot J, Fujimoto C, Amakawa M, Harada M, et al. Implementation of a novel PCR based method for detecting malaria parasites from naturally infected mosquitoes in Papua New Guinea. Malar J. 2009:8:182.

106. Steenkeste N, Incardona S, Chy S, Duval L, Ekala MT, Lim P, et al. Towards high-throughput molecular detection of Plasmodium: new approaches and molecular markers. Malar J. 2009;8:86.

107. Hsiang MS, Lin M, Dokomajilar C, Kemere J, Pilcher CD, Dorsey G, et al. PCR-based pooling of dried blood spots for detection of malaria parasites: optimization and application to a cohort of Ugandan children. J Clin Microbiol. 2010;48:3539-43.

108. Mahende $C$, Ngasala $B$, Lusingu J, Yong TS, Lushino $P$, Lemnge $M$, et al. Performance of rapid diagnostic test, blood-film microscopy and PCR for the diagnosis of malaria infection among febrile children from Korogwe District. Tanzania. Malar J. 2016;15(1):391.

109. Nsobya SL, Parikh S, Kironde F, Lubega G, Kamya MR, Rosenthal PJ, et al. Molecular evaluation of the natural history of asymptomatic parasitemia in Ugandan children. J Infect Dis. 2004;189:2220-6.

110. Jeanne LD, Berry A, Dutoit E, Leclerc F, Beaudou J, Leteurtre S, et al. Molecular method for the diagnosis of imported pediatric malaria. Med Mal Infect. 2010;40:115-8.

111. Hofmann N, Mwingira F, Shekalaghe S, Robinson L, Mueller I, Felger I. Ultrasensitive detection of Plasmodium falciparum by amplification of multi-copy subtelomeric targets. PLoS Med. 2015;12(3):e1001788.

112. Gavina K, Arango E, Larrotta CA, Maestre A, Yanowac SK. A sensitive speciesspecific reverse transcription real-time PCR method for detection of Plasmodium falciparum and Plasmodium vivax. Parasite Epidemiol Control. 2017;2(2):70-6.

113. Lau YL, Lai MY, Fong MY, Jelip J, Mahmud R. Loop-mediated isothermal amplification assay for identification of five human Plasmodium species in Malaysia. Am J Trop Med Hyg. 2015;94:336-9.

114. van Vianen PH, van Engen A, Thaithong S, van der Keur M, Tanke HJ, van der Kaay $\mathrm{HJ}$, et al. Flow cytometric screening of blood samples for malaria parasites. Cytometry. 1993;14:276-80.

115. Hayward R, DeRisi J, Alfadhli S, Kaslow D, Brown P, Rathod P, Shotgun DNA. Microarrays and stage-specific gene expression in Plasmodium falciparum malaria. Mol Microbiol. 2000;35:6-14.

116. World Health Organization. A WHO external quality assurance scheme for malaria nucleic acid amplification testing. 2015. http://www.who.int/malaria/ publications/atoz/9789241509985/en/. Accessed 12 Dec 2017.

117. Hänscheid T, Grobusch M. How useful is PCR in the diagnosis of malaria? Trends Parasitol. 2002;18:395-8.

118. Berna AZ, McCarthy JS, Wang RX, Saliba KJ, Bravo FG, Cassells J, et al. Analysis of breath specimens for biomarkers of Plasmodium falciparum infection. J Infect Dis. 2015;212(7):1120-8. 
119. Oguonu T, Shu E, Ezeonwu BU, Lige B, Derrick A, Umeh RE, et al. The performance evaluation of a urine malaria test (UMT) kit for the diagnosis of malaria in individuals with fever in south-east Nigeria: cross-sectional analytical study. Malar J. 2014:13:1.

120. Oyibo WA, Ezeigwe N, Ntadom G, Oladosu OO, Rainwater-Loveth K, O'Meara W, et al. Multicenter pivotal clinical trial of urine malaria test for rapid diagnosis of Plasmodium falciparum malaria. J Clin Microbiol. 2017 55(1):253-63.

121. Putaporntip C, Buppan P, Jongwutiwes S. Improved performance with saliva and urine as alternative DNA sources for malaria diagnosis by mitochondrial DNA-based PCR assays. Clin Microbiol Infect. 2011;17(10):1484-91.

122. Buppan P, Putaporntip C, Pattanawong U, Seethamchai S, Jongwutiwes S. Comparative detection of Plasmodium vivax and Plasmodium falciparum DNA in saliva and urine samples from symptomatic malaria patients in a low endemic area. Malar J. 2010;9(1):72.

123. Wilson NO, Adjei AA, Anderson W, Baidoo S, Stiles JK. Detection of Plasmodium falciparum histidine-rich protein II in saliva of malaria patients. Am J Trop Med Hyg. 2008;78(5):733-5.

124. Fung AO, Damoiseaux R, Grundeen S, Panes JL, Horton DH, Judy JW, et al. Quantitative detection of pf HRP2 in saliva of malaria patients in the Philippines. Malar J. 2012;11(1):175.

125. Lukianova-Hleb E, Bezek S, Szigeti R, Khodarev A, Kelley T, Hurrell A, et al. Transdermal diagnosis of malaria using vapor nanobubbles. Emerg Infect Dis. 2015;21:1122.

126. McMorrow ML, Aidoo M, Kachur SP. Malaria rapid diagnostic tests in elimination settings - can they find the last parasite? Clin Microbiol Infect. 2011;17(11):1624-31

\section{Submit your next manuscript to BioMed Central and we will help you at every step:}

- We accept pre-submission inquiries

- Our selector tool helps you to find the most relevant journal

- We provide round the clock customer support

- Convenient online submission

- Thorough peer review

- Inclusion in PubMed and all major indexing services

- Maximum visibility for your research

Submit your manuscript at www.biomedcentral.com/submit 